\title{
Analysis of Mixing Used Oil with Solar As Fuel Against Smoke Thickness in Diesel Motors
}

\section{Analisis Pencampuran Oli Bekas dengan Solar Sebagai Bahan Bakar Terhadap Ketebalan Asap pada Motor Diesel}

\author{
Iffarial Nanda ${ }^{1}$, Martias $^{1}$, Toto Sugiarto $^{1}$
}

\begin{abstract}
The purpose of this study was to determine the mix up to what percentage of used oil can be used as fuel against the thickness of diesel engine fumes, in accordance with the Ministry of Environment regulation number 05 in 2016. Opacity meter smoke is used to measure the density of smoke produced by diesel engines during accleration. The sample of fuel used is a mixture with eight kinds of comparison of used oil: diesel. The ratio is 5\%: 95\%, 10\%: 90\%, 15\%: 85\%, 20\%: 80\%, 40\%: 60\%, 60\%: 40\%, 80\%: 20\%, and 100\%: 0\%. From the results of the study it can be concluded that the greater the percentage of mixing of used oil will affect the thickness of the smoke in the diesel motor. Used oil mixture of 5\% to 40\% has smoke thickness which is still within the threshold of exhaust emissions which is below 70\%.
\end{abstract}

\section{Keywords}

smoke opacity, used oil, diesel machine, diesel engine, alternative fuel

\begin{abstract}
Abstrak
Tujuan penelitian ini adalah untuk mengetahui campuran sampai berapa persen oli bekas yang dapat digunakan sebagai bahan bakar terhadap ketebalan asap mesin diesel, sesuai dengan batas ambang peraturan kemenrian lingkungan hidup nomor 05 tahun 2016. Smoke opacity meter digunakan untuk menhukur kepekatan asap yang dihasilkan oleh mesin diesel saat aklerasi. Sampel bahan bakar yang digunakan yaitu campuran dengan delapan macam perbandingan oli bekas : solar. Rationya 5\%:95\%, 10\%:90\%, 15\%:85\%,20\%:80\%, 40\%:60\%,60\%:40\%, 80\%:20\%, dan 100\%:0\%. Dari hasil penelitian dapat disimpulkan bahwa semakin besar pesentase pencampuran oli bekas maka berpengaruh terhadap ketebalan asap pada motor diesel. Campuran oli bekas 5\% sampai dengan $40 \%$ memiliki ketebalan asap yang masih dalam ambang batas emisi gas buang yaitu di bawah $70 \%$.
\end{abstract}

\section{Kata Kunci}

ketebalan asap, oli bekas, motor diesel, mesin diesel, bahan bakar alternatif

${ }^{1}$ Jurusan Teknik Otomotif, Universitas Negeri Padang

Fakultas Teknik, Kampus UNP Air Tawar, Jl. Prof. Dr. Hamka, Padang

*iffalriananda@gmail.com

Submitted : December 13, 2018. Accepted : January 03, 2019. Published : January 15, 2019 


\section{PENDAHULUAN}

Perkembangan teknologi membawa dampak sangat cepat. Salah satu yang berkembang cepat adalah dunia otomotif. Hampir semua masyarakat menggunakan teknologi otomotif setiap harinya, seperti kendaraan dengan mobil, sepeda motor dan lain-lain. Dalam penggunaan mesin kendaraan dan mesin-mesin industri memerlukan minyak pelumas atau sering disebut juga dengan oli. Minyak pelumas adalah suatu zat yang berada di antara dua permukaan yang bergerak secara relative agar dapat mengguranggi gesekan antara dua permukaan.

Sejalan banyaknya mesin-mesin yang menggunakan minyak pelumas membuat jumlah limbah oli bekas meningkat. Tercatat bahwa bengkel-bengkel mobil dan motor setiap harinya menghasilkan oli bekas rata-rata 26,4 liter perhari. Banyaknya oli bekas yang dihasilkan dari kendaraan bermotor dan mobil seringkali menimbulkan permasalahan yang baru. Penanganan minyak pelumas atau oli yang sudah tidak terpakai seringkali dilakukan dengan cara asal-asalan (dengan cara disimpan atau dibuang sembarangan), dan cendrung terabaikan.

Minyak pelumas bekas sendiri, sebenarnya mengandung jumlah sisa hasil pembakaran yang bersifat asam, korosif, deposit, dan logam berat yang bersifat karsinogenik. Berdasarkan kandungan dan sifatnya ${ }_{2}$ pelumas bekas termasuk kategori limbah "bahan berbahaya dan beracun (B3)" yang dikeluarkan oleh kementrian lingkungan hidup (Wahyunisri, 2012).

Berdasarkan sumber dari Direktorat Jenderal Minyak dan Gas (Ditjen Migas), konsumsi minyak pelumas (oli) di Indonesia, baik untuk otomotif maupun mesin-mesin industri mencapai 650 juta liter per tahun dengan peningkatan sekitar 7-10 persen per tahun. Dengan asumsi oli yang terbakar atau terbuang dalam pemakaian mencapai $20 \%$, maka dalam satu tahun diperoleh supply oli bekas sebesar 520 juta liter per tahun atau 1.420 kiloliter per hari dengan harga Rp. 1.000 - 2.000 perliternya. Pelumas atau oli bekas yang mengandung sejumlah zat bisa mengotori udara, tanah dan air.

Minyak pelumas bekas mengandung logam, larutan klorin, dan zat-zat pencemar lainnya. Satu liter minyak pelumas bekas dapat merusak jutaan liter air segar dari sumber air dalam tanah. Berdasarkan, kriteria limbah yang dikelurkan oleh kementrian lingkungan hidup, minyak pelumas bekas termasuk ketegori limbah bahan berbahaya dan beracun (B3). Meski minyak pelumas bekas dapat dimanfaatkan, tapi bila tidak dikelola dengan baik maka bisa membahayakan lingkungan (Wahyuni Sri, 2012). Sebenarnya jika dikaji lebih jauh lagi pelumas atau oli bekas yang dihasilkan oleh bengkel-bengkel kendaraan bermotor maupun industri produksi dapat dipakai menjadi alternativ bahan bakar, mengingat karakteristik setelah dilakukan proses pembersihan dari kotoran mirip dengan light diesel oil (Wahyu , 2007).

Salah satu yang menjadi standar mutu bahan bakar adalah tidak menimbulkan sisa pembakaran yang menimbulakan dampak berbahaya terhadap lingkungan. Apabila bahan bakar Oli bekas dicampur dengan solar akan terjadi kenaikan ketebalan asap pada mesin disel . Pada motor diesel gas sisa pembakaran yang dikeluarkan dari saluran buang kendaraan yang menonjol adalah asap atau yang disebut juga dengan opasitas. Opasitas mempunyai nilai ambang batas yang dikeluarkan oleh Kementerian Lingkungan Hidup Nomor 05 Tahun 2006.

Pada tabel 1 dapat dilihat bahwa ambang batas ketebalan asap opasitas pada motor diesel atau kendaraan kategori $\mathrm{M}, \mathrm{N}$ dan $\mathrm{O}$. Dari beberapa pendapat dan peraturan menteri lingkungan hidup di atas, maka peneliti tertarik untuk melakukan penelitian tentang "Analisis Pencampuran Oli Bekas dengan Solar Sebagai Bahan Bakar Terhadap Ketebalan Asap pada Motor Diesel". 
Tabel 1. Ambang Batas Emisi Gas Buang Kendaraan Bermotor Kategori M, N dan O

\begin{tabular}{|c|c|c|c|c|c|}
\hline \multirow[b]{2}{*}{ Kategori } & \multirow{2}{*}{$\begin{array}{c}\text { Tahun } \\
\text { Pembuatan }\end{array}$} & \multicolumn{3}{|c|}{ Parameter } & \multirow[b]{2}{*}{ Metode Uji } \\
\hline & & $\begin{array}{l}\mathrm{CO} \\
(\%)\end{array}$ & $\begin{array}{c}\mathrm{HC} \\
(\mathrm{ppm})\end{array}$ & $\begin{array}{l}\text { Opasitas } \\
(\% \mathrm{HSU})\end{array}$ & \\
\hline $\begin{array}{l}\text { Berpenggerak motor } \\
\text { bakar cetus api } \\
\text { (bensin) }\end{array}$ & $\begin{array}{l}<2007 \\
\geq 2007\end{array}$ & $\begin{array}{l}4,5 \\
1,5\end{array}$ & $\begin{array}{l}1200 \\
200\end{array}$ & & Idle \\
\hline $\begin{array}{l}\text { Berpenggerak motor } \\
\text { bakar penyalaan } \\
\text { kompresi (diesel) }\end{array}$ & & & & & $\begin{array}{c}\text { Percepatan } \\
\text { bebas }\end{array}$ \\
\hline - $\mathrm{GVW} \leq 3.5$ ton & $\begin{array}{l}<2010 \\
\geq 2010\end{array}$ & & & $\begin{array}{l}70 \\
40\end{array}$ & \\
\hline - $\mathrm{GVW}>3.5$ ton & $\begin{array}{l}<2010 \\
\geq 2010\end{array}$ & & & $\begin{array}{l}70 \\
50\end{array}$ & \\
\hline
\end{tabular}

Sumber: Kementerian Lingkungan Hidup tahun 2006

\section{DASAR TEORI}

\section{Ketebalan Asap}

Menurut kamus besar bahasa Indonesia asap adalah uap yang dapat terlihat yang dihasilkan dari pembakaran. Wiki pedia menjelaskan asap adalah suspense partikel kecil diudara atau (aerosol) yang berasal dari pembakaran taksempurna dari suatu bahan bakar. Granholm (2007: 1) mengemukakan bahwa "Opacity is a measurement of how densethe particulates are in the air and takes into account how much light is obscured by the rising dust. Opacity is measured in percentages from 0 to 100 percent". Dari pernyataan tersebut dijelaskan ketebalan asap adalah ukuran seberapa tebal partikel asap di udara mampu menyerap seberapa banyak cahaya, sehingga cahaya dikaburkan oleh asap. Ketebalan asap diukur dalam persentase dari 0 hingga 100 persen.

Pendapat lain yang lebih spesifik ke mesin diesel dikemukakan oleh Couver (2006:1) "Opacity is a measure of the amount of light obscured by the particulate matter (PM) or soot in the exhaust from diesel engines, measured under normal operating conditions". Dari pernyataan ini dijelaskan ketebalan asap adalah ukuran jumlah cahaya yang dikaburkan oleh partikulat (PM) atau jelaga yang dihasilkan oleh gas buang mesin diesel yang diukur di bawah kondisi normal.

Dari pendapat ahli di atas, ketebalan asap dapat dikatan bahwa ukuran seberapa tebal partikel asap atau jelaga (partikulat) di udara yang dihasilkan oleh gas buang yang mampu menkaburkan jumlah cahaya yang diukur dibawah kondisi normal.

\section{Oli Bekas}

Menurut Keputusan Kepala Badan Pengendalian Dampak Lingkungan commit to user (Bapedal) No. KEP-225/ BAPEDAL/ 08/ 1996, "oli bekas atau selanjutnya disebut minyak pelumas bekas adalah sisa pada suatu kegiatan dan/atau proses produksi”. Oli bekas merupakan limbah kimia berbentuk cairan yang berasal dari kegiatan pemeliharaan alat, pencucian, pencegahan korosi atau inhibitor korosi, pelarutan kerak, dan pengemasan.

\section{Solar}

Solar adalah bahan bakar Jenis distilat berwarna kuning kecoklatan yang jernih. Minyak solar ini biasa disebut juga Gas Oil, Automotive Diesel Oil Atau Hing Speed Diesel. Pengunaan minyak solar pada umumnya adalah untuk bahan bakar pada semua jenis mesin diesel dengan putaran tinggi (diatas $1.000 \mathrm{RPM}$ ), Juga dapat dipergunakan sebagai bahan bakar pada pembakaran langsung dalam dapur-dapur kecil, yang terutama diinginkan pembakaran yang bersih.

Syarat-syarat yang harus dimiliki solar terdiri dari (Toyota, Step 2: 2-5), Yaitu: [1] Sifat nyala yang baik (Flash point). Sifat nyala yang baik adalah sifat yang mudah menyalakan pada saat kompresi tinggi dari mesin diesel, dengan temperatur yang tinggi bahan bakar yang 
disemprotkan akan lebih mudah terbakar, karena dengan bahan bakar solar yang baik titik nyalanya, maka mesin akan lebih mudah dihidupkan dan jalannya mesin lebih halus karena diesel knock (detonasi) lebih kecil. [2] Vikositas yang tepat. Vikositas dari solar bukan hanya mempengaruhi Kemampuan mesin saja tetapi juga akan mempengaruhi injection Pump. Bila vikositas terlalu tinggi, solar akan di alirkan lambat, beban dari injection pomp menjadi besar sehingga leb ih sukar terbakar, kemudian bila angka initerlalu kecil sifat lumasnyamenjadi buruk yang mengakibatkan pelumasan pada injection pump menjadi kecil sekali, dapat menimbulkan panas yang berlebihan pada injection pump. Kemudian apabila viskositas terlalu kecil disemprotkan kedalam selinder, butiran uapnya akan menjadi terlalu kecil sehingga jarak terbang dari udara yang ditekan menjadi lebih pendek, jadi tenaga tekannya menjadi lebih kecil ssehingga campuran dengan udara menjadi jelek dan mengakibatkan pembakaran tidak sempurna. [3]Penguapan adalah Titik penguapan yang tinggi dengan sisa karbon yang sekecil mungkin, bila bagian menguap sedikit, meskipun tidak mempengaruh terhadap mesin akan menyebabkan gas buang menjadi baud an hitam, apabila sisa karbon sesudah pembakaran terlalu banyak diruang bakar maka akan menutup lubang injection nozzle.[4] Mengandung sulfur yang rendah. Sulfur dari bahan bakar solar akan menambah deposite pada silinder dan torak yang mempercepat rusaknya silinder dan pegas torak.

\section{METODE PENELITIAN}

Penelitian ini menggunakan metode eksperimental. Suharsimi (1990: 272) mendefenisikan eksperimental merupakan penelitian yang dimaksudkan untuk mengetahui ada tidaknya akibat dari suatu yang dikenakan pada subjek selidik. Dengan kata lain penelitian eksperimental mencoba meneliti ada tidaknya hubungan sebab akibat, caranya adalah dengan membandingkan satu atau lebih kelompok pembanding yang tidak menerima perlakuan.

\section{Tempat Penelitian}

Tempat pengujian dalam penelitian ini akan dilaksanakan di workshop jurusan Otomotif Fakultas Teknik Universitas Negeri Padang.

\section{Variabel Penelitian}

Variabel Bebas (X) Yang menjadi variable bebas dalam penelitian ini adalah penggunaan bahan bakar oli bekas. Variabel Terikat (Y) Dalam penelitian ini yang menjadi variable terikat adalah ketebalan asap.

\section{Objek Penelitian}

Adapun yang menjadi Objek penelitian ini adalah Motor diesel 4 langkah (Mobil Isuzu Panter TBR 541 LS MT, Tahun 2001 ), 4 silinder dengan kapasitas 2499 cc.

\section{Instrumen Penelitian}

Adapun instrument digunakan dalam penelitian ini adalah: Alat Penelitian yang digunakan adalah, Thermometer digunakan untuk mengetahui temperatur kerja mesin dan temperatur ruangan, Opcity smokemeter, digunakan untuk mengukur ketebalan asap buang motor diesel. Bahan Penelitian Oli bekas yang digunakan ialah : FEDERAL OIL Kekentalan SAE 10W-40, Jenis Oli Mineral

\section{Prosedur Penelitian}

Cara uji pengukuran tingkat kepekatan gas buang kendaraan bermotor jenis motor nyala kompresi. SNI ini menggunakan referensi metode standar dari International Organization for Standardization (ISO) dan Regulasi United Nation for Economic Commission for Europe (UNECE). Langkah - langkah pengujian

1. Periksa Apakah ada kebocoran pada system gas buang motor penggerak dan system alat uji 
2. Naikkan (akselerasi) putaran mesin hingga mencapai $2.500 \mathrm{rpm}$ sampai dengan 3.100 rpm kemudian tahan selama 60 detik dan selanjutnya kembalikan pada kondisi idle

3. Masukkan probe alat uji ke pipa gas buang sedalam $30 \mathrm{~cm}$, bila kurang dari $30 \mathrm{~cm}$ maka pasang pipa tambahan

4. Injak pedal gas maksimum (full throttle) secepatnya hingga mencapai putaran mesin maksimum, selanjutnya tahan 1 hingga 4 detik. Lepas pedal gas dan tunggu hingga putaran mesin kembali stationer. Catat nilai opasitas asap

5. Ulangi proses pengujian 1-4 minimal tiga kali

6. Catat nilai prosentase rata-rata opasitas asap dari proses pengujian dalam satuan persen (\%) yang terukur pada alat uji

\section{Teknik Pengambilan Data}

Teknik pengambilan data adalah melalui pengambilan data secara langsung pada mobil isuzu panther yang sedang diuji dengan menggunakan alat uji Opcity smokemeter yakni data hasil pengujian ketebalan asap. Sedangkan alat pengambilan data berupa tabel-tabel yang selanjutnya di olah sehingga menghasilkan grafik presentase ketebalan asap pada mobil yang di uji.

Hasil perhitungan dilakukan dengan menganalisa hasil penggujian ketebalan asap pada mobil isuzu panther tanpa mencampur solar dengan oli bekas, Oli bekas $5 \%$ dicampur solar $95 \%$, Oli bekas $10 \%$ dicampur solar $90 \%$, Oli bekas $15 \%$ dicampur solar $85 \%$, Oli bekas $20 \%$ dicampur solar $80 \%$, Oli bekas $40 \%$ dicampur solar $60 \%$, Oli bekas $60 \%$ dicampur solar $40 \%$, bekas $80 \%$ dicampur solar 20\%, dan 100\% Oli bekas. Data perhitungan dilakukan ditunjukan pada tabel 8 halaman 40 mengenai data hasil pengujian ketebalan Asap Motor Diesel Isuzu Panther.

\section{Teknik Analisa Data}

Data yang diperoleh dari hasil pengujian diolah dengan mensublitifikan kedalam persamaan yang terdapat pada kajian teori, selanjutnya dilakukan perbandingan dan pengujian statistic.

1. Untuk mengetahui ketebalan asap buang yang dihasilkan oleh kendaraan di peroleh langsung dari pengukuran menggunakan opacity smokemeter, yang dinyatakan dalam satuan persen.

2. Kemudian menganalisis data dengan rumus statistik mean Menganalisa data dalam penelitian ini adalah dengan menggunakan perhitungan statistik mean atau rata rata.

Adapun rumus yang digunakan adalah sebagai berikut :

$$
\bar{X}=\frac{\sum X}{n}
$$

Keterangan:

$$
\begin{array}{ll}
\bar{X} & =\text { Mean (rata-rata) } \\
\sum_{n} x & =\text { Jumlah data setiap spesimen pengujian } \\
& =\text { Banyak pengujian per- spesimen }
\end{array}
$$

3. Setelah didapat rata-ratanya, kemudian membandingkan nilai rata-rata dari masing masing statistik dengan menggunakan teknik statistik deskriptif. Adapun rumus yang digunakan adalah rumus persentase.

$$
\begin{aligned}
& P=\frac{n-N}{n} \times 100 \% \\
& \text { Keterangan: } \\
& \mathrm{P} \quad=\text { Angka persentase yang ingin didapatkan. } \\
& \mathrm{n} \quad=\text { Rata-rata setelah perlakuan pencampuran oli bekas. }
\end{aligned}
$$


$\mathrm{N}=$ Rata-rata sebelum perlakuan/ kondisi standar.

Persentase bertujuan untuk mendapatkan gambaran seberapa besar pecampuran oli bekas dan solar terhadap ketebalan asap dengan kata lain menemukan sesuatu sebagaimana adanya tentang objek yang diteliti.

Uji statistik, untuk melihat perbedaan yang dihasilkan antara pengujian pada mobil yang menggunakan bahan bakar solar,dan oli bekas digunakan uji $t$ ( $t$ test). Berikut rumus t-test yang digunakan:

$$
\begin{aligned}
& t=\frac{(\bar{X}-\bar{Y})-\left(\mu_{X}-\mu_{Y}\right)}{\sqrt{\frac{\left(n_{X}-1\right) S_{X}^{2}+\left(n_{Y}-1\right) S_{Y}^{2}}{n_{X}+n_{Y}-2}}+\sqrt{\frac{1}{n_{X}}+\frac{1}{n_{Y}}}} \\
& \mathrm{Sx}=\sqrt{\frac{\sum\left(x_{\mathrm{i}}-\tilde{x}\right)^{2}}{n-1}}
\end{aligned}
$$

Keterangan:

$\mathrm{t}=$ harga $\mathrm{t}-$ hitung

$\mathrm{H}_{0}=[(\mu x-\mu y)=0]$

$\bar{X}=$ rata-rata sampel ke- 1

$\bar{Y}=$ rata- rata sampel ke- 2

$x_{\mathrm{i}}=$ nilai data

$\mathrm{n}=$ jumlah data

$S_{X}^{2}=$ Standar deviasi sampel 1

$S_{Y}^{2}=$ Standar deviasi sampel 2

$n_{X}$ dan $n_{y}=$ Jumlah Sampel 1 dan 2

HASIL DAN PEMBAHASAN

\section{Hasil}

\begin{tabular}{|c|c|c|c|c|c|}
\hline \multirow{3}{*}{$\begin{array}{l}\text { Putaran } \\
\text { Mesin }\end{array}$} & \multicolumn{5}{|c|}{ Solar $100 \%$} \\
\hline & \multirow{2}{*}{$\begin{array}{l}\text { Tempersatur } \\
\text { Mlesin } \\
\left({ }^{\circ} \mathrm{C}\right)\end{array}$} & \multicolumn{4}{|c|}{ Pengujian Opasitas (\%) } \\
\hline & & Uji 1 & $\mathrm{U}_{j i} 2$ & $\mathrm{Uiji}^{3}$ & Rata-rats \\
\hline $\begin{array}{l}\text { Atsseleteras } \\
\text { i Penuhs }\end{array}$ & $60-70$ & 53.3 & 54.5 & 53.9 & 53.9 \\
\hline \multirow{3}{*}{$\begin{array}{l}\text { Putaran } \\
\text { Mesizan }\end{array}$} & \multicolumn{5}{|c|}{$\frac{1}{1}$ Qli Bekss $5 \%$ sampur Solar $95 \%$} \\
\hline & \multirow{2}{*}{$\begin{array}{l}\text { Temperatur } \\
\text { Alesin } \\
\left({ }^{\circ} \mathrm{C}\right)\end{array}$} & \multicolumn{4}{|c|}{ Pengujian Opasitas (\%) } \\
\hline & & Uii 1 & $\mathrm{U}_{j i} 2$ & $\mathrm{U}_{\mathrm{ii}} 3$ & Rata-rata \\
\hline $\begin{array}{l}\text { Abseleras } \\
\text { i Penuha }\end{array}$ & $60-70$ & 54.5 & 55.4 & 55.2 & - 55 \\
\hline \multirow{3}{*}{$\begin{array}{l}\text { Putaran } \\
\text { Mesing }\end{array}$} & \multicolumn{5}{|c|}{ Qli Belas $10 \%$ sampur Solar $90 \%$} \\
\hline & \multirow{2}{*}{$\begin{array}{l}\text { Tempersatur } \\
\text { Mlesin } \\
\text { ("C) }\end{array}$} & \multicolumn{4}{|c|}{ Pensujian Qpasitas (\%) } \\
\hline & & $\mathrm{U}_{\mathrm{ji}} 1$ & $\mathrm{U}_{\mathrm{ji}} 2$ & $\mathrm{U}_{\mathrm{ji}} 3$ & Rata-rata \\
\hline $\begin{array}{l}\text { Akseleras } \\
\text { i Penuh }\end{array}$ & $60-70$ & 57.9 & 58.4 & 57.9 & 58 \\
\hline
\end{tabular}

Tabel 2. Hasil Pegujian ... bag 1 
Tabel 2. Hasil Pegujian ... bag 2

\begin{tabular}{|c|c|c|c|c|c|}
\hline \multirow{3}{*}{$\begin{array}{l}\text { Putaran } \\
\text { Mesin }\end{array}$} & \multicolumn{5}{|c|}{ Qli Bakas $15 \%$ sampur Solar $85 \%$} \\
\hline & \multirow{2}{*}{$\begin{array}{l}\text { Temperatur } \\
\text { Mesin } \\
\text { ("C) }\end{array}$} & \multicolumn{4}{|c|}{ Pengujian Opasitas (\%) } \\
\hline & & $\mathrm{U}_{\text {ji } 1}$ & Uij 2 & Uji 3 & Rata-rata \\
\hline $\begin{array}{l}\text { Akseleras } \\
\text { i Penuh. }\end{array}$ & $60-70$ & 58.8 & 58.6 & 59.1 & 58.8 \\
\hline \multirow{3}{*}{$\begin{array}{l}\text { Putaran } \\
\text { Mesina }\end{array}$} & \multicolumn{5}{|c|}{ Qli Bekas $20 \%$ campur Solar $80 \%$} \\
\hline & \multirow{2}{*}{$\begin{array}{l}\text { Temperatus } \\
\text { Nerin } \\
\text { ("C) }\end{array}$} & \multicolumn{4}{|c|}{ Pensujian Opasitas (\%) } \\
\hline & & $\mathrm{U}_{\text {ii } 1}$ & Uiji 2 & $\mathrm{U}_{\mathrm{iji}}{ }^{3}$ & Rata-rata \\
\hline $\begin{array}{l}\text { Akseleras. } \\
\text { i Penuh }\end{array}$ & $60-70$ & 59,8 & 59.6 & 59.5 & 59.6 \\
\hline \multirow{3}{*}{$\begin{array}{l}\text { Putaran } \\
\text { Mlesida }\end{array}$} & \multicolumn{5}{|c|}{ Qli Beksas $40 \%$ sampur Solar $60 \%$} \\
\hline & \multirow{2}{*}{$\begin{array}{l}\text { Temperatur } \\
\text { Mlesin } \\
\left({ }^{\circ} \mathrm{C}\right)\end{array}$} & \multicolumn{4}{|c|}{ Pensujian Onasitas (\%) } \\
\hline & & Ujii 1 & Uij 2 & Uij 3 & Rata-rata \\
\hline $\begin{array}{l}\text { Akselecras } \\
\text { i Penuha }\end{array}$ & $60-70$ & 65.8 & 66.4 & 64.8 & 65.6 \\
\hline \multirow{3}{*}{$\begin{array}{l}\text { Putaran } \\
\text { Mesina }\end{array}$} & \multicolumn{5}{|c|}{ Qli Belas $60 \%$ campur Solar $40 \%$} \\
\hline & \multirow{2}{*}{$\begin{array}{l}\text { Temperatur } \\
\text { Mlesid } \\
\text { ("C) }\end{array}$} & \multicolumn{4}{|c|}{ Pengujian Opasitas (\%) } \\
\hline & & Uii 1 & Uji 2 & $\mathrm{Ujii}^{3}$ & Rata-rata \\
\hline $\begin{array}{l}\text { Akselersas } \\
\text { i Penuh }\end{array}$ & $60-70$ & 74.8 & 77.6 & 76.2 & 76.2 \\
\hline $\begin{array}{l}\text { Akselexas } \\
\text { i Penuh. }\end{array}$ & $60-70$ & 74.8 & 77.6 & 76.2 & 76.2 \\
\hline \multirow{3}{*}{$\begin{array}{l}\text { Putarsa } \\
\text { Mersin }\end{array}$} & \multicolumn{5}{|c|}{ Qli Bekas $80 \%$ campur Solar $20 \%$} \\
\hline & \multirow{2}{*}{$\begin{array}{l}\text { Temperatur } \\
\text { Mesing } \\
\text { ("C) }\end{array}$} & \multicolumn{4}{|c|}{ Pensujian Qpassitas (\%) } \\
\hline & & Uij 1 & Uii 2 & $\mathrm{Ujii}^{3}$ & Rata-rata \\
\hline $\begin{array}{l}\text { Akseleras } \\
\text { i Penuh }\end{array}$ & $60-70$ & 85.6 & 87.4 & 87.9 & 86.9 \\
\hline \multirow{3}{*}{$\begin{array}{l}\text { Putarsan } \\
\text { Mesina }\end{array}$} & \multicolumn{5}{|c|}{ Qli $100 \%$} \\
\hline & \multirow{2}{*}{$\begin{array}{l}\text { Temperatur } \\
\text { Dlesing } \\
\text { ("C) }\end{array}$} & \multicolumn{4}{|c|}{ Penguijian Onasitas (\%) } \\
\hline & & $\mathrm{U}_{\text {ji } 1} 1$ & Uii 2 & $\mathrm{Ujii}^{3}$ & Rata-rata \\
\hline $\begin{array}{l}\text { Akseleras. } \\
\text { i Penuh. }\end{array}$ & $60-70$ & 96.8 & 97.9 & 95.4 & 96.7 \\
\hline
\end{tabular}

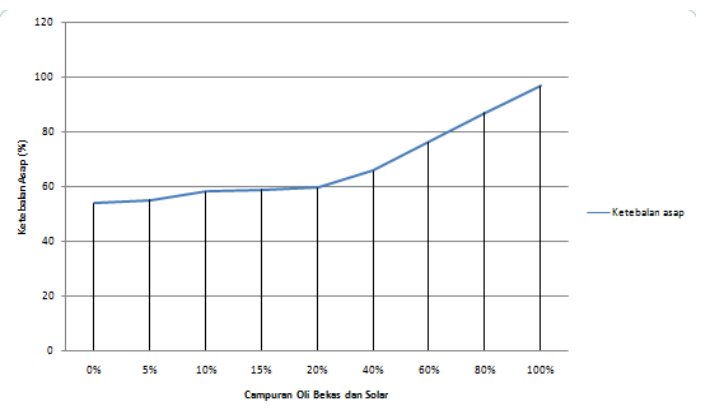

Gambar 1. Grafik Hasil Pengujian

Berdasarkan Grafik Pada Gambar 1 dapat di lihat bahwa semakin banyak oli bekas di campur dengan solar maka ketebalan asap naik. Sedangkan peraturan ambang batas ketebalan asap yang dikeluarkan kementrian lingkungan hidup nomor 5 tahun 2006 yaitu ketebalan asap yang izinkan di bawah 70\%.

\section{Analisis Ketebalan Asap}

Berdasarkan hasil pengujian ketebalan asap pada motor diesel panther dengan pencampuran oli bekas dan solar, dengan pencampuran oli bekas 5\%, 10\%, 15\%, 20\%, 40\%, $60 \%, 80 \%, 100 \%$ kemudian dilakukan pengujian ketebalan asap dengan menggunakan smoke opacity yang dapat dilihat pada tabel 23 serta pada gambar grafik 87, berdasarkan penelitian 
yang dilakukan didapat hasil pengujian ketebalan asap bahwa semakin meningkatnya ketebalan asap sesuai dengan meningkatnya campuran oli bekas dan solar, hal tersebut tentu akan mempengaruhi tinggkat polusi udara atau ketebalan asap kendaraan yang telah ditetapkan berapa besar ambang batas ketebalan asap yang dperbolehkan oleh kementrian lingkungan hidup Nomor 05 Tahun 2006. Berikut ini Ambang Batas Emisi Gas Buang Kendaraan Bermotor Kategori M, N dan 0.

Tabel 3. Batas ambang kepekatan asap

\begin{tabular}{|c|c|c|c|c|c|}
\hline \multirow[b]{2}{*}{ Kategori } & \multirow[b]{2}{*}{$\begin{array}{c}\text { Tahun } \\
\text { Pembuatan }\end{array}$} & \multicolumn{3}{|c|}{ Parameter } & \multirow[b]{2}{*}{ Metode Uii } \\
\hline & & $\begin{array}{l}\mathrm{CO} \\
(\%)\end{array}$ & $\begin{array}{c}\mathrm{HC} \\
(\mathrm{ppm})\end{array}$ & $\begin{array}{l}\text { Opasitas } \\
(\% \mathrm{HSU})\end{array}$ & \\
\hline $\begin{array}{l}\text { Berpenggerak motor } \\
\text { bakar cetus appi } \\
\text { (bensin) }\end{array}$ & $\begin{array}{l}<2007 \\
\geq 2007\end{array}$ & $\begin{array}{l}4,5 \\
1,5\end{array}$ & $\begin{array}{l}1200 \\
200\end{array}$ & & Idle \\
\hline $\begin{array}{l}\text { Berpenggerak motor } \\
\text { bakar penvalaan } \\
\text { kompresi (diesel) }\end{array}$ & & & & & $\begin{array}{c}\text { Percepatan } \\
\text { bebas }\end{array}$ \\
\hline - GVW $\leq 3.5$ ton & $\begin{array}{l}<2010 \\
\geq 2010\end{array}$ & & & $\begin{array}{l}70 \\
40\end{array}$ & \\
\hline - GVW $>3.5$ ton & $\begin{array}{l}<2010 \\
\geq 2010\end{array}$ & & & $\begin{array}{l}70 \\
50\end{array}$ & \\
\hline
\end{tabular}

Sumber: Kementerian Lingkungan Hidup tahun 2006

\section{SIMPULAN DAN SARAN}

\section{Simpulan}

Dari hasil Penelitian Campuran oli bekas 5\% sampai dengan 40\% ketebalan asap yang dihasilkan masih dalam ambang batas emisi gas buang sesuai dengan Peraturan kementerian lingkungan hidup nomor 5 tahun 2006 yaitu ketebalan asap di bawah 70\%

\section{Saran}

Penelitian ini hanya mengukur ketebalan asap, penelitian selanjutnya diharapkan untuk mengetahui daya dan torsi motor diesel empat langkah. Selanjutnya penulis juga sarankan agar dilakukan suatu metode penyaringan oli bekas agar didapatkan karakteristik yang mendekati solar, dan meneliti krakteristik oli bekas yang sudah di saring.

\section{DAFTAR RUJUKAN}

[1]Couver, Van. 2006. Air Pollution. Department of Motor Vehicle.

[2]Kepala Badan Pengendalian Dampak Lingkungan. 1996. "Tata Cara Dan Persyaratan Penyimpanan Dan Pengumpulan Minyak Pelumas Bekas" (http//www.IND-PUU-7-1996Kepka Bapedal No 255 Tahun 1996.ac.id), diakses 29 Agustus 2017.

[3]Menteri Lingkugan Hidup. 2006. "Peraturan Menteri Lingkungan Hidup No 05 Tahun 2006 Tentang Ambang Batas Emisi Gas Buang Kendaraan Tipe Baru".(http://103.52.213.225/hukum/simppulhk/public/uploads/files/pERMEN\%20lh\%2 ONO\%205).pdf, diakses 19 Okt 2017.

[4]Suharsimi Arikunto. 1990. Manajemen Penelitian. Jakarta: PT Rineka Cipta

[6]Toyota. 1972. Meteri Pelajaran Engine Grup New Step 1. Jakarta: PT Toyota Astra Motor.

[7]Wahyu Purwo Raharjo. 2007. "Pemanfaatan Tea (Three Ethyl Amin) Dalam Proses Penjernihan Oli Bekas Sebagai Bahan Bakar Pada Peleburan Aluminium" (https://publikasiilmiah.ums.ac.id), diakses 11 Oktober 2017. JTM. USM Vol 08 